\title{
Malignant Phyllodes Tumor in Ectopic Breast Tissue: A Case Report with a Literature Review
}

\section{Abstract}

Supernumerary breasts come from ectopic breast tissue which regression was incomplete. Typically, it is a single supernumerary gland, located in the axilla. Ectopic breast tissue is subject to the same pathologic events that occur in normally positioned breasts. Excision may be required for diagnosis, treatment of symptoms or cosmesis. We report a case report of a female patient aged 22 years, without medical history. She consulted for a left axillary swelling. Breast ultrasound showed: Voluminous mass of axillary tail with polylobed contours, Aspect evoking a phyllodes tumor. The patient had a wide excision. Anapath review concluded: Malignant phyllodes tumor in ectopic breast tissue and absence of residual tumor. Abdominal ultrasound and chest x-ray were normal. Adjuvant systemic treatment and radiotherapy were not delivered. Our patient is regularly followed: She doesn't develop distant metastases or loco-regional relapse. Axillary ectopic breast tissue may provide a diagnostic challenge, as other benign and malignant lesions occur in this area. Malignant Phyllodes tumor in ectopic breast tissue is an extremely rare occurrence. Wide breast surgery is the mainstay of the treatment of non-metastatic malignant phyllodes tumors of the breast.

Keywords: Breast; Phyllode tumor; Ectopic breast tissue

Received: December 29, 2017; Accepted: January 16, 2018; Published: January 23, 2018

\section{Introduction}

Polymastia (supernumerary breasts) is a congenital condition in which abnormal accessory breast tissue is found in addition to normal breast tissue. Accessory breast results in any anomaly of develop of the embryological milk lines, which run from the anterior axillary folds to the inner thighs [1]. Patients may be misdiagnosed prenatally as having a lipoma, lymphadenopathy, or hidradenitis suppurativa [2]. This is ectopic breast tissue is the seat of the same pathologic events that occur in normally located breast tissue, both benign and malignant $[3,4]$. Ectopic breast tissue is often unassociated with a distinct areola or nipple, so it may not be evident. We report the case of a patient operated on an axillary mass of $6 \mathrm{~cm}$. She had a large lumpectomy. Pathological examination concluded to a malignant phyllode tumor in supernumerary breast. The patient had smooth postoperative recoveries.

\section{Case Presentation}

A 22-year-old woman presented with no medical history. She

\section{Imen Znagui*, Slimani Olfa, Attia Moez, Ben Temim Riadh, Makhlouf Taher, Mathlouthi Nabil and Attia Leila}

\author{
Department of Gynecology, Charles Nicolle \\ Hospital, Tunisia
}

\section{*Corresponding author: Imen Znagui \\ 巨imenznaguib@gmail.com}

Department of Gynecology, Charles Nicolle Hospital, Tunisia.

Tel: 0021692915252

Citation: Znagui I, Olfa S, Moez A, Riadh BT, Taher M, et al. (2018) Malignant Phyllodes Tumor in Ectopic Breast Tissue: A Case Report with a Literature Review. Arch Cancer Res. Vol.6 No.1:1 


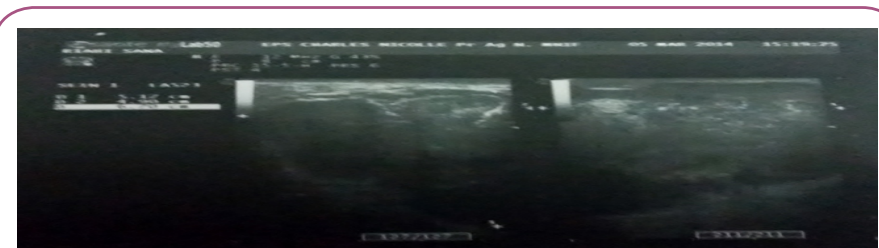

Figure 1 Phyllode tumor on ectopic axillary breast.

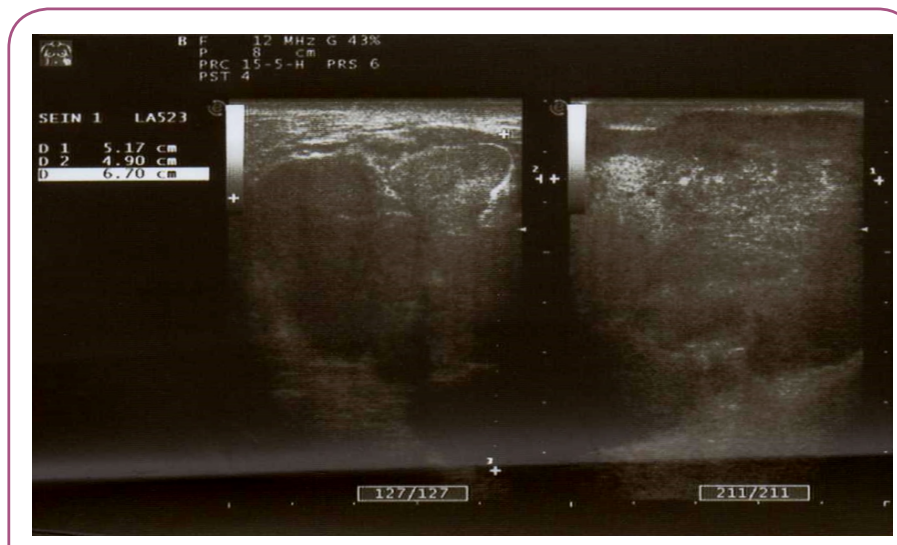

Figure 2 Phyllode tumor on ectopic axillary breast.

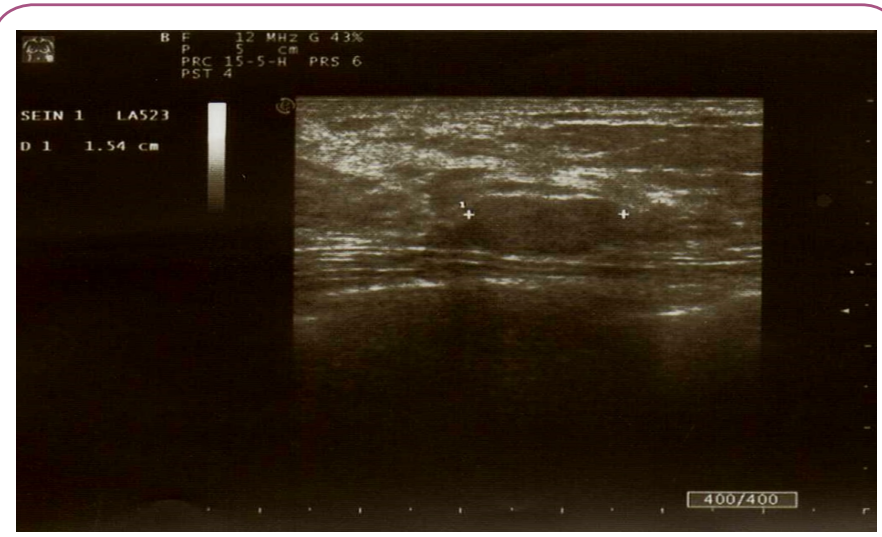

Figure 3 Right subareal mass recalling an adenofibroma.

adjuvant therapy. An extension assessment with chest x-ray and abdominal ultrasound showed no abnormalities. The evolution was favorable with regular clinical and monthly ultrasound monitoring.

\section{Discussion}

Interruption of galactophoric duct migration from the axillary trough to the mid-clavicular line can occur in $2 \%$ to $6 \%$ of female embryos resulting in ectopic localization of breast tissue. Approximately $67 \%$ of accessory breast tissue occurs in the thoracic or abdominal portions of the milk line, often just below the inframammary crease and more often on the left side of the body, another $20 \%$ occurs in axilla [5]. Many family cases have been reported [6-8]. One theory is that an autosomal dominant gene of variable expressivity is inherited that inhibits normal regression of the embryonic mammary ridge [2]. In our observation, no family history was found. These breasts are subject to the usual physiological changes of the reproductive cycle; it can grow during pregnancy, give milk during milky rise even without associated nipple, and undergo pathological changes especially malignant. Primary breast cancer in accessory axillary tissue is rare [9]. In practice, it is never diagnosed preoperatively because the axilla is rarely included in the mammogram and the diagnosis of hidradenitis is the most frequent. Axillary breast cancer is a rare finding, accounting for $0.3 \%$ of all breast cancers [10]. All histological types may be encountered, with a higher frequency of ductal carcinomas. Marshall et al. [9] and Nihon-Yanagi et al. [10] found a greater frequency of medullary carcinomas and a relative rarity of invasive lobular carcinomas. In our observation, the pathological examination concluded that there was a malignant phyllode tumor on supernumerary breast.

Malignant phyllodes of breast tumors are fibroepithelial tumors that account for less than $1 \%$ of breast cancers [11]. The histological aspect of a benign or intermediate phyllode tumor can sometimes be confused with an adenofibroma. Unlike adenofibroma, the phyllode tumor has stromal hyperplasia and a biphasic foliage appearance.

The presence of cohesive stromal cells (phyllodes fragments), isolated mesenchymal cells, and clusters of hyperplastic duct cells, foreign body giant cells, blood vessels crossing the stromal fragments, and bipolar naked nuclei and the absence of apocrine metaplasia are highly suggestive of a phyllodes tumor. The presence of malignant cells of mesenchymal morphology within a breast tissue is suggestive of malignant phyllode tumor.

However, cells of similar morphology may be suggestive of metaplastic carcinoma or mammary sarcoma, hence the importance of histological analysis that allows the realization of immuno-histochemical analyzes.

At the time of diagnosis of axillary breast cancer, lymph node involvement is present in half of the cases. The main differential diagnosis is metastatic adenocarcinoma. The presence of mammary tissue with ducts and lobules is necessary to make the diagnosis of ectopic breast cancer and to eliminate lymph node metastasis from an occult mammary tumor. Cutaneous changes are most often found [10].

Excision of ectopic breast tissue should not be systematic. On the other hand, in the event of a deleterious genetic mutation of BRCA1 or BRCA2 or of functional signs (discomfort, pain, swelling), its ablation is generally proposed. Surgical excision of accessory breast cancer in the form of a large lumpectomy associated with lymph node dissection is the technique of choice [12]. Complementary mastectomy is controversial. Adjuvant treatments for mammary cancers on accessory glands are like breast cancer.

For malignant phyllodes tumors, the case of our observation, the treatment is based on breast surgery with the attention to ensure the complete character of the excision as evidenced by the low percentage of local recurrence observed in the MD series. Anderson Cancer Center (3\%) [13]. The radiosensitivity of malignant phyllodes tumors was first suggested by several 
clinical cases in local relapse or metastases [14-16]. Nevertheless, the role of adjuvant radiotherapy in malignant phyllodes tumors remains uncertain [17]. The poor prognosis of ectopic breast cancer in the axillary situation is due to the delay diagnosis and the earlier lymph node extension due to the proximity of the tumor and lymph nodes.

\section{Conclusion}

Polymastia is a rare malformation whose axillary localization

\section{References}

1 Abita T, Lachachi F, Durand-Fontanier S, Maisonnette F, Valleix D, et al. (2004) A propos dun cas de seins surnumeraires axillaires bilateraux. Morphologie 88: 39-40.

2 Anthony LT, Viera J (1997) Breast-feeding with ectopic axillary breast tissue. Mayo Clin Proc 74: 1021-1022.

3 Amsler E, Sigal-Zafrani B, Marinho E, Aractingi S (2002) Carcinome mammaire ectopique primitif axillaire. Ann Dermatol Venereol 129: 1389-1391.

4 Da Silva BB, Rodriques JS, Borges US, Pires CG, Pereira da Silva RF (2006) Large mammary hamartoma of axillary supernumerary breast tissue. Breast 15: 135-136.

5 Nayak S, Acharjya B, Devi B (2007) Polymastia of axillae. Indian J Dermatol 52: 118-120.

6 Weinberg SK, Motulsky AG (1976) Aberrant axillary breast tissue: A report of family with six affected women in two generations. Clin Genet 10: 325-328.

7 Brown J, Schwartz RA (2004) Supernumerary nipples and renal malformations: A family study. J Cutan Med Surg 8: 170-172.

8 Galli-Tsinopoulou A, Krohn C, Schmidt H (2001) Familial polythelia over three generations with polymastia in the youngest girl. Eur J Pediatr 160: 375-377. can be confused with other causes of axillary masses. Any supernumerary breast should have the same monitoring as the breast and appropriate radiographic projections. Any modification of the supernumerary breast should be taken into consideration so as not to miss out on the occurrence of cancer.

\section{Conflict of Interest}

The authors declare that they have no conflict of interest that competes with any of the contents of the manuscript.

9 Marshall MB, Moynihan JJ, Evans RT (1994) Ectopic breast cancer: Case report and literature review. Surg Oncol 3: 295-304.

10 Nihon-Yanagi Y, Ueda T, Kameda N, Okazumi S (2009) A case of ectopic breast cancer with a literature review. Surg Oncol 20: 1-8.

11 Tavassoli FA, Devilee P (2003) Pathology and genetics of tumors of the breast and female genital organs. Lyon: International Agency for research on Cancer Press 99-103.

12 Cogswell H, Czemy E (1961) Carcinoma of aberrant breast of the axilla. Am Surg 27: 388-390.

13 Chaney AW, Pollack A, McNeese MD, Zagars GK, Pisters PW, et al. (2000) Primary treatment of cystosarcoma phyllodes of the breast. Cancer 89: 1502.

14 Eich PD, Diederich S, Eich HT, Micke O, Wagner W (2000) Diagnostic radiation oncology: Malignant cystosarcoma phylloides. Strahlenther Onkol 176: 192-195.

15 Riepl M, Strnad V (1994) Radiochemotherapy in the liver metastases of cystosarcoma phyllodes. Strahlenther Onkol 170: 668-672.

16 Stockdale AD, Leader M (1987) Phyllodes tumour of the breast: Response to radiotherapy. Clin Radiol 38: 287.

17 Haberer S, Lae M, Seegers V, Pierga JY, Salmon R, et al. (2009) Prise en charge des tumeurs phyllodes malignes du sein : I experience de l'institut Curie. Cancer/Radiothérapie 13: 305-312. 